\title{
Trimetazidine and Cellular Response in Cardiopulmonary Bypass*
}

\author{
Gerez Fernandes Martins" ${ }^{1 \#}$, Aristarco G. de Siqueira Filho², João Bosco de F. Santos ${ }^{1}$, \\ Claudio Roberto Cavalcanti Assunção ${ }^{1}$, Alberto Valência ${ }^{1}$, Gerez Martins ${ }^{1}$ \\ ${ }^{1}$ Cardiac Surgery Department, Institute of Cardiology State Aloysio de Castro, Rio de Janeiro, Brasil \\ ${ }^{2}$ Cardiology Department, Federal University of Rio de Janeiro, Rio de Janeiro, Brasil \\ Email: "gerezm@cardiol.br
}

Received November 24, 2012; revised December 22, 2012; accepted January 5, 2013

Copyright (C) 2013 Gerez Fernandes Martins et al. This is an open access article distributed under the Creative Commons Attribution License, which permits unrestricted use, distribution, and reproduction in any medium, provided the original work is properly cited.

\begin{abstract}
Background: Organic cellular inflammatory response constitutes a pathophysiological mechanism present in all Coronary Artery Bypass Graftings (CABGs). In this aspect, the organism brings forth its defenses through answers that involve cellular components. Objectives: To evaluate, in a randomized double-blind prospective study, controlled with placebo, the effects of trimetazidine (Tmz) on cellular response, analyzed through the variation of leukocytes, neutrophils and monocytes. Patients and Method: 30 patients were randomly selected to be studied, with no more than a mild ventricular dysfunction, and divided into two groups (Tmz and placebo) stratified by echocardiography and receiving medication/placebo in a $60 \mathrm{mg} / \mathrm{day}$ dose. The samples of leukocytes, neutrophils and monocytes were obtained in the pre-operatory day without medication, at surgery day with 12 to 15 days of medication/placebo, with 5 minutes after the aortic declamping, and within 12, 24 and 48 hours after surgery. Results: The leukocytes and neutrophils levels have decreased significantly in the treated group when compared to the control group, in all analyzed moments $(\mathrm{p}=$ 0.012; $p=0.005$ ). Conclusions and Clinical Implications: Trimetazidine has proved to reduce significantly the levels of total leukocytes and neutrophils in patients submitted to CABG.
\end{abstract}

Keywords: Trimetazidine; Administration and Dosage; Myocardial Reperfusion; Inflammation; Cellular Response; Myocardial Revascularization

\section{Introduction}

The modernization of cardiac surgery was driven by the development of extracorporeal circulation (ECC) on the late 1950s. This technique became indispensable for the majority of cardiac surgeries, although associated with an undesirable systemic inflammatory response [1].

This inflammatory response is mediated by the release of humoral and cellular immunological factors, allowing analysis through the activation of the complement system, thrombin, cytokines, neutrophils, intercellular adhesion molecules (ICAMs), mast cells and other mediators that manifest themselves in many different ways $[2,3]$.

Leukocytes, components of the cellular response, are partially driven off the circulation through their binding to the ECC circuit, and are also diluted by the fluid that

\footnotetext{
*Academic Linking: This article is a part of Gerez Fernandes Martins's Ph.D. Thesis, at Federal University of Rio de Janeiro's State (Universidade Federal do Estado do Rio de Janeiro).

${ }^{\#}$ Corresponding author.
}

fills up the circuit [2].

Three main types of leukocytes are activated in the initial stage of ECC: neutrophils, monocytes and lymphocytes [4]. The neutrophils are activated by the components of the complement cascade (C3a and C5a) as well as the contact system (kallikrein and factor XIIf). The activated $\mathrm{C} 3$ and $\mathrm{C} 5$ manifest themselves after seconds of exposure to the ECC circuit, interacting with the neutrophils. In this context, other mediators also activate the neutrophils, such as thrombin, TNF- $\alpha$, heparin, endotoxine, histamine, and the neutrophil activator peptide 2 , which is liberated through the platelets. Finaly, neutrophils can also be activated by the direct interaction with the endothelial cells, assuming a very important role in the late stage of the inflammatory response. A similar effect occurs in almost every specific subgroup of lymphocytes, including B lymphocytes, natural killer (NK) lymphocytes, T-helper lymphocytes and T-supressor lymphocytes. The total amount of lymphocytes decreases progressively, as the CABG-ECC goes on [2,5]. 
In CABG-ECC, the monocytes are also activated, although more slowly than in other systems, as the complement and the neutrophil ones, having an activity spike a few hours after the beginning of surgery [6] . The activation mechanism of the monocytes is still not well known, acting independently as well as associating with platelets, constituting the monocyte-platelet aggregation $[7,8]$.

By the end of the ECC, reperfusion, a physiopathological phenomenon that intensifies the inflammatory response after the aortic declamping, starts to act as a second wave of aggression related to the inflammatory insult in CABG $[3,4,9]$.

The reperfusion's physiopathology_and its relation to the inflammatory response-involves several substances produced by the neutrophils and monocytes with subsequent degranulation. The monocytes produce and release IL-1, IL-2, IL-3, IL-6 and IL-8 [9,10]. The neutrophils produce and release the so called hyperoxide radicals, that consist in the superoxide anion $\left(\mathrm{O}^{2}\right)$, the hydroxyl radical $(\mathrm{OH})$ and hydrogen peroxide $\left(\mathrm{H}^{2} \mathrm{O}^{2}\right)$, and also proteinases, eicosanoid lipids, adhesion molecules, IL-1, IL-6 and IL-8, causing direct damage to the myocardium [11-14].

Trimetazidine (1-(2,3,4-trimethoxy-benzyl) piperacillin hydrochloride) with its anti-ischemic action, reduces the metabolic damage caused during ischemia by acting on a critical step of cardiac metabolism, blocking betaoxidation of fatty acids by inhibiting the long-chain 3acetyl-CoA thiolase. That anti-ischemic effect increases glucose oxidation, additional to glycolysis, with the consequent reduction in protons, elevation of the intracellular $\mathrm{pH}$ and tissue acidosis, recovery of the cardiac efficiency, and improvement in the production of acetylCoA. In addition, it limits calcium build-up, inflammation and the production of superoxide free radicals that occur after reperfusion, without causing hemodynamic changes.

During inflammatory response the neutrophils release the cytotoxic content held in their granules, resulting in an increase in vascular permeability, the formation of an interstitial edema, thrombosis and parenchymal cell injury $[14,15]$. This has been perceived in the lungs, the heart and in other tissues and organs during CABG-ECC. Most investigators consider that neutrophils play a central role in tissues and organs injuries as a result of ECC $[16,17]$.

Taking into account the leukocytes' action in the inflammatory response triggered by CABG-ECC, this research evaluates the effects of the trimetazidine (Tmz) substance on the cellular response involving myocardial reperfusion, through the plasmatic variation of total leukocites, neutrophils and monocytes by the end of surgery and in post-operatory.

\section{Methods}

Prospective clinic trial, double-blinded, randomized and controlled by placebo, held in the State's Institute of Cardiology Aloysio de Castro, Rio de Janeiro (IECACRJ) from July 2007 to August 2008. The main purpose was to examine the differences in the level of leukocytes, neutrophils and monocytes, components of the inflamematory response in CABG-ECC, evaluating two groups, one treated with trimetazidine $(\mathrm{Tmz})$ and the other with placebo.

Martins et al. [11] have analyzed 137 patients with signs of CABG-ECC, diagnosed through an echocardiogram, from which 75 with mild dysfunction or normal ventricular function were selected. From those 75, 60 patients, allocated in the Tmz and placebo groups concluded the trial for exam of the serological markers of myocardial injury troponin- $\mathrm{T}$ and $\mathrm{Cpk}-\mathrm{Mb}$. From this first trial 15 patients from each group were selected randomly for the present research, using the computer program Cytools Excel Add-in for dosage of the following cellular components of inflammatory response: total leukocytes, neutrophils and monocytes.

The Tmz was supplied to the patients after being masked with randomization in the proportion $1: 1$, interchanged in blocks by the computer program Cytools Excel add-in. The evaluators had no knowledge of which patients have had Tmz or placebo. The statistical studies were also made blindly, with other codes referring to Tmz/placebo, cracked only after statistical analysis.

The patients have received the $60 \mathrm{mg}$ dose of medication/placebo divided into three daily intakes, begun within 12 and 15 days before the surgical procedure, all of them remaining with the drug/placebo intake for five to eight days after the surgery, totaling twenty days of medication/placebo usage. During this study, no side effects were detected that could be associated with trimetazidine.

The patients were submitted to an elective surgical treatment by a technique that involved transsternal median sternotomy, dissection of the internal mammary artery, saphenous vein stripping, longitudinal pericardiotomy, with the introduction of cannulas in the aorta and only one drain for the cava, in that sequence. The anastomoses of saphenous vein grafts were performed by two techniques. The first, distal anastomosis with occlusive clamping (tangential) of the aorta and cardiac arrest in anoxia, performing the distal and then still in circulation with tangential clamping of the aorta and proximal anastomosis. The second with occlusive aortic clamping for distal and proximal anastomoses. The extracorporeal circulation was held within a central moderated hypothermia $\left(32^{\circ} \mathrm{C}-34^{\circ} \mathrm{C}\right)$, and the myocardial protection established by a hypothermical blood cardioplegia $\left(4^{\circ} \mathrm{C}\right)$, infused in the aorta roots or directly into the coronary 
sinus. All the patients had a balanced general anesthesia, venous inhaling in closed circuit, with $\mathrm{CO}_{2}$ absorber (Soda-Lime) and mechanical ventilator. As an inhalation agent an isofluorane was used, with $50 \%$ oxygen blended with nitrous oxide. Of the venous drugs, the ones used were the hypnotics etomidate and midazolam; as opioid, fentanyl; and as muscle relaxant, pancuronium bromide.

The samples for total leukocytes, neutrophils and monocytes were collected at IECAC-RJ (Brownstein Laboratories) at the following stages: in the absence of drugs in pre-operatory, 5 minutes after aortical declamping straight from the right atrium, and within 12, 24 and 48 hours after the surgical procedure, gathered in a central vein and analyzed by the ABX Pentra 60 (Horiba) equipment using three techniques: cytochemistry, impedance and photometric absorption. The results were checked through slide-reading by a qualified technician.

The adopted criterium for significance determination was the $5 \%$ level. The statistical analysis was processed by the SAS 6.04 software (SAS Institute, Inc., Cary, NC), using the following methods: for a comparison of numeric variables between both groups a Student's t-test was used, or the Mann Whitney test. In the comparison of categorial variables between both groups a Chi-square $\left(\chi^{2}\right)$ test or the Fisher's exact test was applied. In order to compare the behavior of variables in time per each of the treatment groups, a variance (ANOVA) for repeated measures analysis was made. The Bonferroni's multiple comparison test was applied to identify the moments in which they differed among themselves and between the two groups.

The study was approved by the IECAC-RJ Ethical Committee for Research. Its participants signed the Informed Consent term and were monitored until medical discharge.

The drug and the research material were provided by the author. The randomization, masking and usage of software were coordinated by a certified pharmacist of Federal University of Rio de Janeiro.

\section{Results}

\subsection{General Profile of Sample}

Table 1 presents the general profile of thirty selected patients for inflammatory markers' analysis, comparing the Tmz and placebo groups. Significant differences were not found between the two groups, implying homogeneity.

Table 2 shows the basal inflammatory variables analysis in which it can be verified that there is uniformity between the groups Tmz and placebo selected for the trial.

Table 3 shows the analysis of the surgical variables. As it can be observed for the clinical and inflammatory
Table 1. Clinical variations according to $\mathrm{Tmz}$ and placebo groups.

\begin{tabular}{|c|c|c|c|c|c|}
\hline \multirow{2}{*}{ Variations } & \multicolumn{2}{|c|}{ Tmz } & \multicolumn{2}{|c|}{ Plac } & \multirow{2}{*}{ p value } \\
\hline & $\mathbf{N}$ & $\%$ & $\mathbf{N}$ & $\%$ & \\
\hline Males & 10 & 66.7 & 12 & 80.0 & 0.34 \\
\hline Years (average \pm SD) & \multicolumn{2}{|c|}{$59.0 \pm 7.8$} & \multicolumn{2}{|c|}{$59.3 \pm 5.8$} & $0.91^{\mathrm{a}}$ \\
\hline Trivascular $^{\mathrm{b}}$ disease & 11 & 73.3 & 10 & 66.7 & 0.50 \\
\hline Diabetes mellitus & 2 & 13.3 & 2 & 13.3 & 0.70 \\
\hline HAS & 9 & 60.0 & 10 & 66.7 & 0.50 \\
\hline Previous MI & 3 & 20.0 & 5 & 33.3 & 0.34 \\
\hline Smoker or former smoker & 7 & 46.7 & 10 & 66.7 & 0.23 \\
\hline
\end{tabular}

SD: Standard Deviation; HAS: Arterial Hypertension; MI: Myocardial infarct. ${ }^{\mathrm{a}}$ Student's t-test for independent samples; ${ }^{\mathrm{b}}$ Comparison of the trivascular disease related to the bivascular.

variables, the groups also were homogeneous as to surgical procedures and ICU time.

Tables $\mathbf{4}$ and $\mathbf{5}$ show the analysis of the surgical variables of non-selected patients for this trial that were treated with $\mathrm{Tmz}$ and with placebo and the ones that were randomly selected, as described in the methodology section. It may be observed that the groups do not present significant differences in any of the analyzed variables.

\subsection{Analysis of the Leucocytes by Groups}

As it is shown in Figures 1 and 2, in the analysis of the leucocytes by groups, the levels of total leucocytes and of neutrophils are significantly inferior in the Tmz group, when compared to the placebo group (leucocytes, $\mathrm{p}=$ 0.012 , and neutrophils, $p=0.005$ ). The same occurred in the evolution of these values when analyzed over time in each group separately $(\mathrm{p}=0.0001)$.

In Figure 3, it is asserted that the evolution of the monocytes levels in time happened significantly in each group singly $(\mathrm{Tmz} p=0.003$ and Placebo $\mathrm{p}=0.0001$ ). However, when compared, the groups haven't substantially differed $(p=0.25)$.

\section{Discussion}

Leucocytes changes are present in all cardiovascular surgeries, increasing when extracorporeal circulation is utilized. In the last few decades, not many studies have analyzed the impact of drugs in the reduction of neutrophils and monocytes and its correlation to clinical outcomes in the post-operatory.

In this research, thirty patients indicated for CABG, bearing bi- and trivascular lesions and with regular or mildly compromised ventricular function, evaluated by a bidimensional transtoracic echocardiogram [18], were randomly selected. The inflammatory response was analyzed through the following elements of cellular response: total leukocytes, neutrophils and monocytes in a prospec- 
Table 2. Basal inflammatory variables analysis according to the group.

\begin{tabular}{|c|c|c|c|c|c|c|c|c|}
\hline Basal variable & Group & $\mathbf{n}$ & Average & SD & Median & Minimum & Maximum & p value $^{\mathrm{a}}$ \\
\hline \multirow{2}{*}{ Leucocytes (u/L) } & $\mathrm{Tmz}$ & 15 & 7220.0 & 1394.5 & 7300 & 4900 & 10600 & \multirow{2}{*}{0.37} \\
\hline & Plac & 15 & 6738.4 & 1502.1 & 6400 & 4700 & 9500 & \\
\hline \multirow{2}{*}{ Neutrophils $(u / L)$} & $\operatorname{Tmz}$ & 15 & 4010.0 & 653.6 & 4095 & 2745 & 5124 & \multirow{2}{*}{0.48} \\
\hline & Plac & 15 & 3798.3 & 956.8 & 3623.2 & 2592 & 5696 & \\
\hline \multirow{2}{*}{ Monocytes (u/L) } & $\operatorname{Tmz}$ & 15 & 560.7 & 119.8 & 552 & 279 & 750 & \multirow{2}{*}{0.81} \\
\hline & Plac & 15 & 543.6 & 260.1 & 540 & 128 & 1012 & \\
\hline
\end{tabular}

SD: Standard Deviation. 'Student's t-test for independent samples, or Mann-Whitney's.

Table 3. Analysis of the surgical variables according to Tmz and placebo groups.

\begin{tabular}{|c|c|c|c|c|c|c|c|c|}
\hline Variable & Group & $\mathbf{n}$ & Average & SD & Median & Minimum & Maximum & $p$ value \\
\hline \multirow{2}{*}{ Time of anoxia } & $\mathrm{Tmz}$ & 15 & 66.3 & 23.2 & 58 & 37 & 120 & \multirow{2}{*}{0.22} \\
\hline & Plac & 15 & 58.3 & 23.8 & 50 & 30 & 100 & \\
\hline \multirow{2}{*}{ Time of ECC } & $\operatorname{Tmz}$ & 15 & 82.7 & 24.2 & 80 & 43 & 130 & \multirow{2}{*}{0.56} \\
\hline & Plac & 15 & 77.3 & 23.1 & 75 & 50 & 120 & \\
\hline \multirow{2}{*}{ Cardiopl. volume } & $\mathrm{Tmz}$ & 15 & 170.7 & 45.3 & 160 & 50 & 250 & \multirow{2}{*}{0.52} \\
\hline & Plac & 15 & 162.7 & 59.3 & 150 & 100 & 300 & \\
\hline \multirow{2}{*}{ No. of bypass } & $\mathrm{Tmz}$ & 15 & 2.87 & 0.74 & 3.0 & 2 & 4 & \multirow{2}{*}{0.74} \\
\hline & Plac & 15 & 2.93 & 0.59 & 3.0 & 2 & 4 & \\
\hline \multirow{2}{*}{ Hours in ICU } & $\mathrm{Tmz}$ & 15 & 72.8 & 7.1 & 72 & 60 & 96 & \multirow{2}{*}{0.25} \\
\hline & Plac & 15 & 78.4 & 14.8 & 72 & 60 & 120 & \\
\hline
\end{tabular}

SD: Standard Deviation.

Table 4. Analysis of the surgical variables according to the selected and non-selected groups treated with Tmz.

\begin{tabular}{|c|c|c|c|c|c|c|c|c|}
\hline Variable & Selected & $\mathbf{n}$ & Average & SD & Median & Minimum & Maximum & p value \\
\hline \multirow{2}{*}{ Time of anoxia } & Yes & 15 & 66.3 & 23.2 & 58 & 37 & 120 & \multirow{2}{*}{0.78} \\
\hline & No & 15 & 65.5 & 19.0 & 63 & 34 & 100 & \\
\hline \multirow{2}{*}{ Time of ECC } & Yes & 15 & 82.7 & 24.2 & 80 & 43 & 130 & \multirow{2}{*}{0.33} \\
\hline & No & 15 & 74.5 & 19.5 & 75 & 40 & 110 & \\
\hline \multirow{2}{*}{ Cardiopl. volume } & Yes & 15 & 170.7 & 45.3 & 160 & 50 & 250 & \multirow{2}{*}{0.61} \\
\hline & No & 15 & 165.3 & 54.0 & 150 & 100 & 250 & \\
\hline \multirow{2}{*}{ No. of bypass } & Yes & 15 & 2.87 & 0.74 & 3.0 & 2 & 4 & \multirow{2}{*}{0.74} \\
\hline & No & 15 & 2.93 & 0.59 & 3.0 & 2 & 4 & \\
\hline \multirow{2}{*}{ Hours in ICU } & Yes & 15 & 72.8 & 7.1 & 72 & 60 & 96 & \multirow{2}{*}{0.17} \\
\hline & No & 15 & 76.8 & 9.9 & 72 & 72 & 96 & \\
\hline
\end{tabular}

SD: Standard Deviation.

tive protocol that had as a goal to examine the effects of trimetazidine $(\mathrm{Tmz})$ in reducing these elements after the reperfusion and in the subsequent post-operatory.

The cellular components in CABG-ECC were analyzed in the moments considered of most clinical significance, that is, in pre-operatory without drugs, when this markers should not be altered; five minutes after aortic declamping, that characterizes the myocardial reperfusion moment by recirculation of the hyperoxide radicals, having the samples collected directly in the right atrium in the surgical field; and within 12, 24 and 48 hours in deep catheter positioned at the right atrium $[19,20]$.

The routine medications used as a treatment for coronary disease by the patients until the surgery day, when compared between groups, did not reveal significant dissimilarities. It is also important to highlight that in post-operatory there were no complications and that the 
Table 5. Analysis of the surgical variables according to the selected and non-selected groups treated with Tmz.

\begin{tabular}{|c|c|c|c|c|c|c|c|c|}
\hline Variable & Placebo & $\mathbf{n}$ & Average & SD & Median & Minimum & Maximum & $p$ value \\
\hline \multirow{2}{*}{ Age (years) } & Yes & 15 & 59.3 & 5.8 & 58 & 46 & 67 & \multirow{2}{*}{0.11} \\
\hline & No & 15 & 63.1 & 7.2 & 66 & 51 & 72 & \\
\hline \multirow{2}{*}{ Time of anoxia } & Yes & 15 & 58.3 & 23.8 & 50 & 30 & 100 & \multirow{2}{*}{0.19} \\
\hline & No & 15 & 67.8 & 28.2 & 60 & 42 & 156 & \\
\hline \multirow{2}{*}{ Time of ECC } & Yes & 15 & 77.3 & 23.1 & 75 & 50 & 120 & \multirow{2}{*}{0.37} \\
\hline & No & 15 & 85.9 & 30.9 & 80 & 45 & 179 & \\
\hline \multirow{2}{*}{ Cardiopl. volume } & Yes & 15 & 162.7 & 59.3 & 150 & 100 & 300 & \multirow{2}{*}{0.20} \\
\hline & No & 15 & 187.3 & 53.4 & 170 & 120 & 300 & \\
\hline \multirow{2}{*}{ No. of bypass } & Yes & 15 & 2.93 & 0.59 & 3.0 & 2 & 4 & \multirow{2}{*}{0.40} \\
\hline & No & 15 & 3.13 & 0.74 & 3.0 & 2 & 4 & \\
\hline Hours in ICU & No & 15 & 75.2 & 11.5 & 72 & 60 & 96 & 0.58 \\
\hline
\end{tabular}

SD: Standard Deviation.

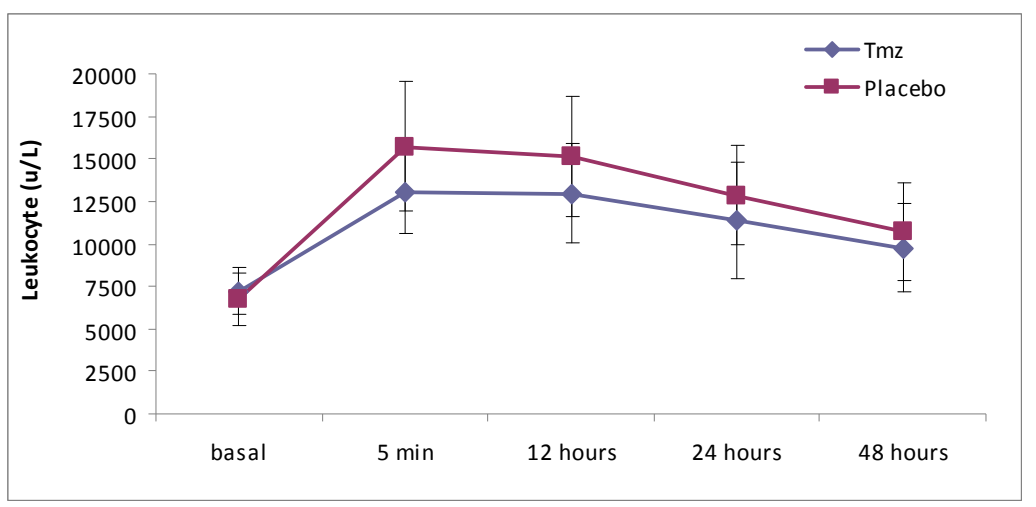

Figure 1. Leukocyte over time according to treatment group.

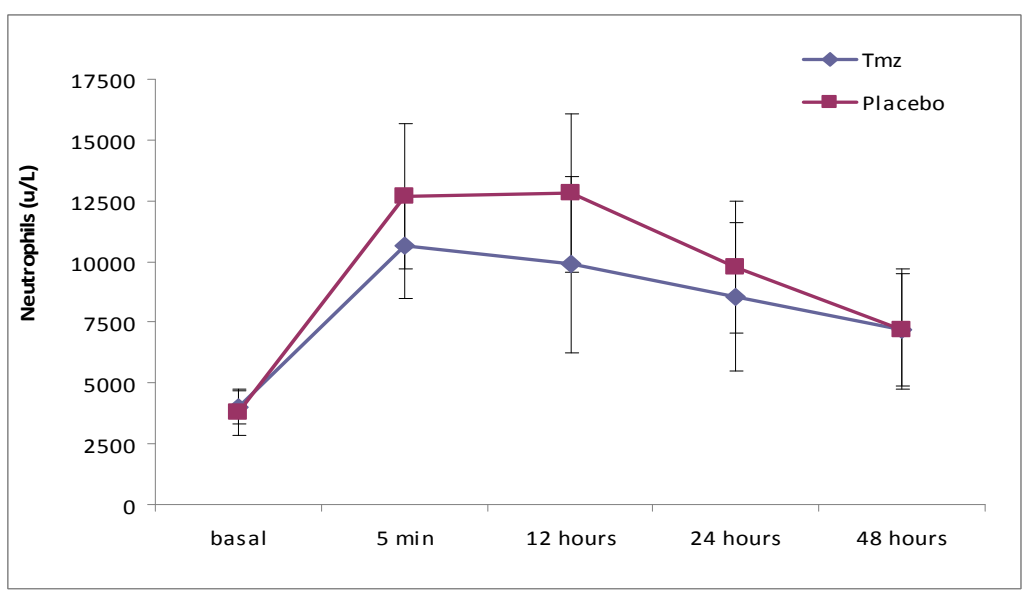

Figure 2. Neutrophil $(\mathrm{u} / \mathrm{L})$ over time according to treatment group.

patients didn't need support with amines, transfusions or any other additional therapy.

The comparison of clinical and basal leukocytary variables between the groups did not demonstrate significant differences (Tables 1 and 2), staying within nor- mality. Some authors describe a major incidence of atrial fibrillation when comparing patients with leukocytes elevation in pre-operatory, therefore making it necessary to observe changes in these components prior to surgery $[21,22]$. 


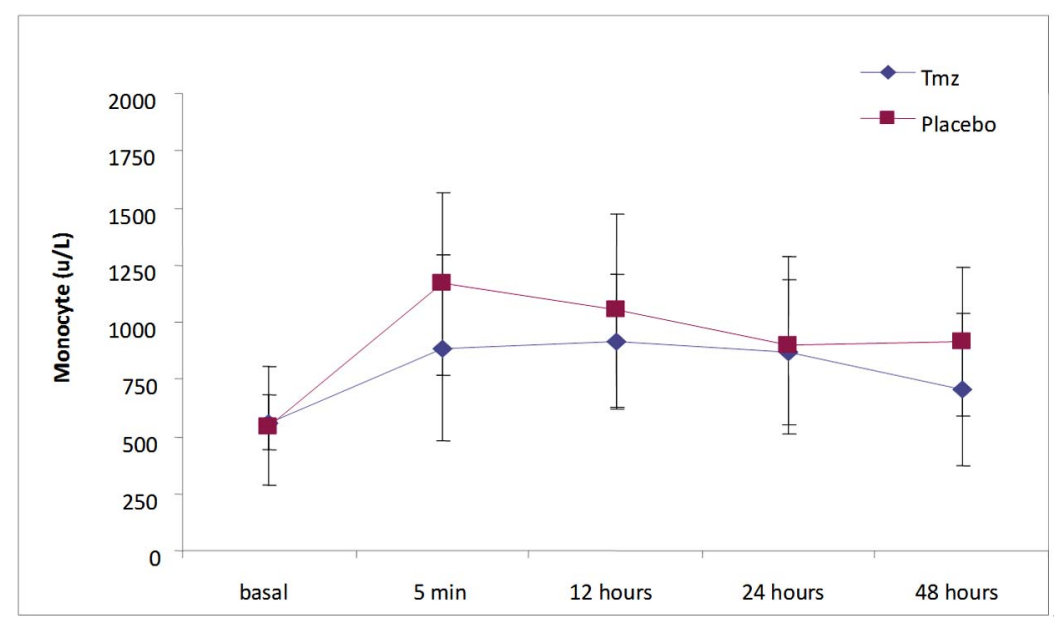

Figure 3. Monocytes $(u / L)$ in time according to treatment group.

Albert et al. [21] analyzed the leukocytes values in pre-operatory in 7483 patients undertaking CABG-ECC, to examine the relation between elevated basal levels of leukocytes and the occurrence of an encephalic vascular accident (EVA). The authors verified that the pre-operatory values of leukocytes above $9 \times 10^{3} / \mathrm{L}$ were significantly related to the incidence of EVA in post-operatory.

Fontes et al. [22] (2009) have analyzed a cohort of patients aged $\geq 60$ years, submitted by choice to CABGECC, their values of CRP and leukocytes having been evaluated prospectively up until the second day of postoperatory, and also the relation of these values to the development of atrial fibrillation. Values of total leukocytes over $7 \times 10^{3} / \mathrm{L}$ in pre-operatory have shown to be an independent predictor in the prevalence of atrial fibrillation.

The analysis of the surgical variables in the present study (Table 3) demonstrated that there aren't significant differences between the $\mathrm{Tmz}$ and the placebo groups. The time of ECC and the aortic clamping time were similar between the groups, also being inferior to the ones described in the literature [19,23].

With the main goal of verifying eventual differences between study patients from Martins et al. [11] selected for this trial and the ones not selected, the analysis was extended to a comparison between these two groups not revealing, however, significant differences (Tables 4 and $5)$.

Some studies have demonstrated that leukocytes variations during the initial stage of $\mathrm{CABG}$ include the reduction of the serum $\mathrm{C} 3$ and $\mathrm{C} 4$ levels with concomitant increase in the levels of $\mathrm{C} 3 \mathrm{a}, \mathrm{C} 3 \mathrm{~b}$ and $\mathrm{C} 5 \mathrm{a}$; increase in histamine and IL8; and the loss of neutrophils, eosinophils and basophils in the circuit and the peripheral blood, most likely through their migration to the subendothelial tissue stimulated by the inflammatory response $[24,25]$.
The ischemia-reperfusion injury plays a very important part in the mediation of the complement's activation [12]. The membrane attack complex (MAC) that grows in the final stage is observed more rapidly when reperfusion occurs. The association between neutrophils, endothelium and complement, the action of The complement in adhesion and infiltration of neutrophils, as well as the relation among complement, mitochondria and ischemia followed by reperfusion, are topics that address the reperfusion relation to the activation of the complement pathways in oxidative stress. It might be considered that the activation of the complement plays an essential role in the initial stage of the inflammatory response at CABG-ECC, being this action the stimulation for neutrophils activation [26].

When the physiopathological aspects of cardiovascular surgeries with and without ECC are analyzed in trials that compare the pro- and anti-inflammatory effects of these procedures, smaller inflammatory damages in the procedures without ECC become evident, with lesser increase in the polymorphonuclear leukocytes, but with no reduction of clinical outcomes of great magnitude such as mortality, strokes, myocardial infarctions and the need for reintervention $[20,27,28]$.

In this essay, while analyzing the total leukocytes, neutrophils and monocytes in five distinct moments (5 minutes, 6, 12, 24 and 48 hours), it was verified that the total leukocytes varied significantly when compared with the groups in the sample collecting hiatus, with lower values in the Tmz group relative to the placebo group ( $\mathrm{p}$ $=0.012$ ). Neutrophils also presented significantly low values in the Tmz group $(p=0.005)$. Monocytes values, however, did not achieve statistical significance when compared to the groups over the studied moments in time $(\mathrm{p}=0.25)$.

Utoh et al. [29] observed in patients submitted to CABG-ECC, conversions in complement and isolation of 
leukocytes. The drop in the levels of neutrophils was verified in the initial stage of ECC, and an increase in the leukocytes with neutrophil predominance happened during the first post-op day.

Lamm et al. [30] analyzed 253 patients in a prospective study, submitted to cardiac surgery, establishing the incidence of atrial fibrillation in $39.1 \%$ related to a spike of $16.3+/-6.5 \times 10^{9} / \mathrm{L}$ from total post-operative leukocytes.

In this study, the analyses of leukocytes and neutrophils showed a significant raise of their levels in both groups in the moment of the aorta declamping. The maximum values were achieved at reperfusion and kept through 12 hours, not surpassing the values described in the Lamm [30] study, with progressive fall until 48 hours later, when they reached averages closer to normality, as observed in trials that compare cardiac surgery with and without ECC [1,20,31].

The inflammatory effects in CABG-ECC include the release of interleukin 6 and 8 and the complements $\mathrm{C} 3 \mathrm{a}$ and $\mathrm{C} 5 \mathrm{a}$, that will act over the bone marrow cells, stimulating the production and release of leukocytes in the vascular bed increasing its levels in peripheral blood after aortic unclamping $[29,32,33]$.

Little is known of the Tmz effects over the leukocytes dynamics in inflammatory response. Williams et al. [34] analyzed experimentally the inhibition of neutrophils by Tmz after myocardial ischemia injury and reperfusion, bearing evidence of a major myocardial accumulation of neutrophils after three hours from reperfusion, as well as circulating neutrophils in the control group.

Martins et al. [35] evaluated in a prospective doubleblind randomized and placebo controlled study, the effects of Tmz on the inflammatory response, by using the variation in interleukins 6 and 8 , TNF- $\alpha$, complements $\mathrm{C} 3$ and C5, and highly sensitive C-reactive protein (HSCRP) levels in the pre-and post-operative periods. The authors showed that interleukin 6 levels were significantly lower in the group treated as compared with those in the control group at all time points assessed and side effects were not found in any of the patients included in the study.

Monti et al. [36] analyzed experimentally the Tmz action in blocking the release of endothelin-1. This action has as consequence a major nitrate production, leading to vasodilatation, but still demands more clarification as to the effects produced over neutrophils.

Tritto et al. [37] demonstrated that Tmz is able to curb the activation of neutrophils and that the substance gives protection over injury mediated by them in ischemic hearts.

Based on significant differences in the leukocytes and neutrophils levels between the group treated with Tmz and the placebo group observed in this study, it is possi- ble to suggest that $\mathrm{Tmz}$ does have a protective effect over the cardiac cell in ischemia injury and reperfusion, leading to the reduction of the myocardial aggression markers, of oxidative stress and, as a consequence, of inflammatory response, limiting calcium accumulation, acidosis, the production of hyperoxide radicals and interleukin, resulting in a clinical benefit [11,37-40].

CABG-ECC is a good model to evaluate inflammation and the ischemia and reperfusion effect $[20,37,38]$ when, with intermittent hypothermic cardioplegic solution, we attempt to protect the heart isolated in prolonged asystole. For this reason, the additional effect of Tmz as a pretreatment in this process was also evaluated.

\section{Conclusions}

Trimetazidine, when administered as a pre-treatment to patients of CABG-ECC with intermittent hypothermic cardioplegia, promotes a decrease in the cellular response in inflammation, demonstrated by a significant reduction in total leukocytes and neutrophils.

Dedications: I would like to thank Prof. Dr. Alexandre Lourenço Lopes (Pharmacology) for the placebo production, attendance to the masking process and randomization of the clinical essay; Prof. Rafael Nunes for blood analyses and organization of laboratorial results; and Prof. Dr. Maria do Carmo Lourenço-Gomes (Linguistics) for the text review of the Portuguese version of this article.

\section{REFERENCES}

[1] J. Larmann and G. Theilmeier, "Inflammatory Response to Cardiac Surgery: Cardiopulmonary Bypass versus NonCardiopulmonary Bypass Surgery," Best Practice \& Research Clinical Anaesthesiology, Vol. 18, No. 3, 2004, pp. 425-438. doi:10.1016/j.bpa.2003.12.004

[2] S. Wan, J. L. LeClerc and J. L. Vincent, "Inflammatory Response to Cardiopulmonary Bypass Mechanisms Involved and Possible Therapeutic Strategies," Chest, Vol. 112, No. 3, 1997, pp. 676-692. doi:10.1378/chest.112.3.676

[3] A. L. S. Brasileiro, "A injúria de Reperfusão Miocárdica," A Revista da SOCERJ, Vol. 10, No. 2, 1997, pp. 79-88.

[4] L. H. Edmunds, "Inflammatory Response to Cardiopulmonary Bypass," The Annals of Thoracic Surgery, Vol. 66 , No. 5, 1998, pp. S12-S16. doi:10.1016/S0003-4975(98)00967-9

[5] J. R. S. Day and K. M. Taylor, "The Systemic Inflammatory Response Syndrome and Cardiopulmonary Bypass," International Journal of Surgery, Vol. 3, No. 2, 2005, pp. 129-140. doi:10.1016/j.ijsu.2005.04.002

[6] P. E. Greilich, C. F. Brouse, H. M. Rinder, et al., "Monocyte Activation in On-Pump versus Off-Pump Coronary Artery Bypass Surgery," Journal of Cardiothoracic and Vascular Anesthesia, Vol. 22, No. 3, 2008, pp. 361-368. doi:10.1053/j.jvca.2007.08.009 
[7] M. Nijziel, R. V. Oerle, C. Van'tVeer, et al., "Tissue Factor Activity in Human Monocytes Is Regulated by Plasma: Implications for the High and Low Responder Phenomenon," British Journal of Haematology, Vol. 112, No. 1, 2001, pp. 98-104. doi:10.1046/j.1365-2141.2001.02545.x

[8] N. Maugeri, M. Brambilla, M. Camera, et al., "Human Polymorphonuclear Leukocytes Produce and Express Functional Tissue Factor upon Stimulation," Journal of Thrombosis and Haemostasis, Vol. 4, No. 6, 2006, pp. 1323-1330. doi:10.1111/j.1538-7836.2006.01968.x

[9] T. Pintar and C. D. Collard, "The Systemic Inflammatory Response to Cardiopulmonary Bypass," Anesthesiology Clinics of North America, Vol. 21, No. 3, 2003, pp. 453464. doi:10.1016/S0889-8537(03)00039-7

[10] T. Kawamura, R. Wakusawa, K. Okada, et al., "Elevation of Cytokines during Open Heart Surgery with Cardiopulmonary Bypass: Participation of Interleukin 8 and 6 in Reperfusion Injury," Canadian Journal of Anesthesia, Vol. 40, No. 11, 1993, pp. 1016-1021. doi:10.1007/BF03009470

[11] G. F. Martins, A. G. Siqueira-Filho, J. B. F. Santos, et al., "Trimetazidina na Injuria de Isquemia e Reperfusão em Cirurgia de Revascularização do Miocárdio," Arquivos Brasileiros de Cardiologia, Vol. 97, No. 3, 2011, pp. 209-216. doi:10.1590/S0066-782X2011005000079

[12] A. L. Moens, M. Claeys, J. Timmermans, et al., "Myocardial Ischemia/Reperfusion-Injury a Clinical View on a Complex Pathophysiological Process," International Journal of Cardiology, Vol. 100, No. 2, 2004, pp. 179190. doi:10.1016/j.ijcard.2004.04.013

[13] J. G. Laffey, J. F. Boylan and D. C. H. Cheng, "The Systemic Inflammatory Response to Cardiac Surgery," Anesthesiology, Vol. 97, No. 1, 2002, pp. 215-252. doi:10.1097/00000542-200207000-00030

[14] G. L. J. Vermeiren, M. J. Claeys, D. V. Bockstaele, et al., "Reperfusion Injury after Focal Myocardial Ischemia: Polymorphonuclear Leukocyte Activation and Its Clinical Implications," Ressuscitation, Vol. 45, No. 1, 2000, pp. 35-61. doi:10.1016/S0300-9572(00)00168-4

[15] C. D. Collard and S. Gelman, "Pathophysiology, Clinical Manifestations, and Prevention of Ischemia-Reperfusion Injury," Anesthesiology, Vol. 94, No. 6, 2001, pp. 11331138. doi:10.1097/00000542-200106000-00030

[16] H. Kin, Z. Q. Zhao, H. Y. Sun, et al., "Post Conditioning Attenuates Myocardial Ischemia-Reperfusion Injury by Inhibiting Events in the Early Minutes of Reperfusion," Cardiovascular Research, Vol. 62, No. 1, 2004, pp. 7475. doi:10.1016/j.cardiores.2004.01.006

[17] O. J. Warren, A. J. Smith, C. Alexiou, et al., "The Inflammatory Response to Cardiopulmonary Bypass: Part 1-Mechanisms of Pathogenesis," Journal of Cardiothoracic and Vascular Anesthesia, Vol. 23, No. 2, 2009, pp. 223-231. doi:10.1053/j.jvca.2008.08.007

[18] D. M. Cerqueira, J. N. Weissman and V. Dilsizian, "Standardized Myocardial Segmentation and Nomenclature for Tomographic Imaging of the Heart," Circulation, Vol. 105, No. 4, 2002, pp. 539-542. doi: $10.1161 / \mathrm{hc} 0402.102975$

[19] A. Diegeler, N. Doll, T. Rauch, et al., "Humoral Immune
Response during Coronary Artery Bypass Grafting," Circulation, Vol. 102, No. 19, 2000, pp. III95-III100. doi:10.1161/01.CIR.102.suppl 3.III-95

[20] C. V. Serrano Jr., J. A. Souza, N. H. Lopes, et al., "Reduced Expression of Systemic Proinflammatory and Myocardial Biomarkers after Off-Pump versus On-Pump Coronary Artery Bypass Surgery: A Prospective Randomized Study," Journal of Critical Care, Vol. 25, No. 2, 2010, pp. 305-312. doi:10.1016/j.jcrc.2009.06.009

[21] A. A. Albert, C. J. Beller, J. A. Walter, et al., "Preoperative High Leukocyte Count: A Novel Risk Factor for Stroke after Cardiac Surgery," The Annals of Thoracic Surgery, Vol. 75, No. 5, 2003, pp. 1550-1557. doi:10.1016/S0003-4975(02)04376-X

[22] M. L. Fontes, D. Amar, A. Kulak, et al., "Increased Preoperative White Blood Cell Count Predicts Postoperative Atrial Fibrillation after Coronary Artery Bypass Surgery," Journal of Cardiothoracic and Vascular Anesthesia, Vol. 23, No. 4, 2009, pp. 484-487. doi:10.1053/j.jvca.2009.01.030

[23] C. W. Whitten, G. E. Hill, R. Ivy, et al., "Does the Duration of Cardiopulmonary Bypass or Aortic Cross-Clamp, in the Absence of Blood and/or Blood Product Administration, Influence the IL-6 Response to Cardiac Surgery," Anesthesia \& Analgesia, Vol. 86, No. 1, 1998, pp. 28-33.

[24] J. McGuinness, D. Bouchier-Hayes and J. M. Redmond, "Understanding the Inflammatory Response to Cardiac Surgery,” Surgeon, Vol. 6, No. 3, 2008, pp. 162-171. doi:10.1016/S1479-666X(08)80113-8

[25] J. R. S. Day and K. M. Taylor, "The Systemic Inflammatory Response Syndrome and Cardiopulmonary Bypass," International Journal of Surgery, Vol. 3, No. 2, 2005, pp. 129-140. doi:10.1016/i.ijsu.2005.04.002

[26] J. E. Jordan, Z. Q. Zhao and V. J. Johansen, "The Role of Neutrophils in Myocardial Ischemia-Reperfusion Injury," Cardiovascular Ressearch, Vol. 43, No. 4, 1999, pp. 860878. doi:10.1016/S0008-6363(99)00187-X

[27] J. Bucerius, J. F. Gummert, M. A. Borger, et al., "Stroke after Cardiac Surgery: A Risk Factor Analysis of 16,184 Consecutive Adult Patients," The Annals of Thoracic Surgery, Vol. 75, No. 2, 2003, pp. 472-478. doi:10.1016/S0003-4975(02)04370-9

[28] J. Nissinen, F. Biancari, J. Wistbacka, et al., "Safe Time Limits of Aortic Cross-Clamping and Cardiopulmonary Bypass in Adult Cardiac Surgery," Perfusion, Vol. 24, No. 5, 2009, pp. 297-305. doi:10.1177/0267659109354656

[29] J. Utoh, T. Yamamoto, T. Kambara, et al., "Complement Conversion and Leukocyte Kinetics in Open Heart Surgery," The Japanese Journal of Surgery, Vol. 18, No. 3, 1988, pp. 259-267. doi:10.1007/BF02471442

[30] G. Lamm, J. Auer and J. Weber, "Postoperative White Blood Cell Count Predicts Atrial Fibrillation after Cardiac Surgery," Journal of Cardiothoracic and Vascular Anesthesia, Vol. 20, No. 1, 2006, pp. 51-56. doi:10.1053/i.jvca.2005.03.026

[31] M. H. L. Souza and D. O. Elias, "Resposta Inflamatória Sistêmica à Circulação Extracorpórea," Anaesthesiology, 
1999, Vol. 90, No. 1, pp. 72-80.

[32] J. F. M. Pruijt, P. Verzaal, R. Van Os, et al., "Neutrophils Are Indispensable for Hematopoietic Stem Cell Mobilization Induced by Interleukin- 8 in Mice," Proceedings of the National Academy of the Sciences of the United States of America, Vol. 99, No. 9, 2002, pp. 6228-6233. doi:10.1073/pnas.092112999

[33] I. U. Schraufstatter, R. G. DiScipio, M. Zhao, et al., "C3a and C5a Are Chemotactic Factors for Human Mesenchymal Stem Cells, Which Cause Prolonged ERK1/2 Phosphorylation," The Journal of Immunology, Vol. 182, No. 6, 2009, pp. 3827-3836. doi:10.4049/jimmunol.0803055

[34] F. M. Williams, K. Tanda, M. Kus, et al., "Trimetazidine Inhibits Neutrophil Accumulation after Myocardial Ischemia and Reperfusion in Rabbits," Journal of Cardiovascular Pharmacology, Vol. 22, No. 6, 1993, pp. 828-833. doi:10.1097/00005344-199312000-00008

[35] G. F. Martins, A. G. Siqueira-Filho, J. B. F. Santos, et al., "Trimetazidine and Inflammatory Response in Coronary Artery Bypass Grafting," Arquivos Brasileiros de Cardiologia, Vol. 99, No. 2, 2012, pp. 688-696. doi:10.1590/S0066-782X2012005000066

[36] L. D. Monti, S. Allibardi, P. M. Piatti, et al., "Triglycerides Impair Postischemic Recovery in Isolated Hearts: Roles of Endothelin-1 and Trimetazidine," The American
Journal of Physiology-Heart and Circulatory Physiology, Vol. 281, No. 3, 2001, pp. H1122-H1130.

[37] I. Tritto, P. Wang, P. Kuppusamy, et al., "The Anti-Anginal Drug Trimetazidine Reduces Neutrophil-Mediated Cardiac Reperfusion Injury," Journal of Cardiovascular Pharmacology, Vol. 46, No. 1, 2005, pp. 89-98. doi:10.1097/01.fjc.0000164091.81198.a3

[38] B. M. Matata, A. W. Sosnowski and M. Galinanes, "Off-Pump Bypass Graft Operation Significantly Reduces Oxidative Stress and Inflammation," The Annals of Thoracic Surgery, Vol. 69, No. 3, 2000, pp. 785-791. doi:10.1016/S0003-4975(99)01420-4

[39] K. A. Kaminski, T. A. Bonda, J. Korecki, et al., "Oxidative Stress and Neutrophil Activation-The Two Keystones of Ischemia/Reperfusion Injury," International Journal of Cardiology, Vol. 86, No. 1, 2002, pp. 41-59. doi:10.1016/S0167-5273(02)00189-4

[40] P. Di Napoli, P. Di Giovanni, M. A. Gaeta, et al., "Trimetazidine and Reduction in Mortality and Hospitalization in Patients with Ischemic Dilated Cardiomyopathy: A Post Hoc Analysis of the Villa Pini D’Abruzzo Trimetazidina Trial," Journal of Cardiovascular Pharmacology, Vol. 50, No. 5, 2007, pp. 585-589. doi:10.1097/FJC.0b013e31814fa9cb 